\title{
Meteorologists Meeting Rainmakers: Indigenous Knowledge and Climate Policy Processes in Kenya
}

\author{
Paul Guthiga and Andrew Newsham*
}

Abstract This article seeks to shed light on policy processes arising from interaction between indigenous rainmakers and meteorologists, in participatory action research aimed at increasing the capacity of a local community to adapt to climate change. Policy processes were analysed from the perspective of actors, their narratives and interests. At the beginning of the project, the interactions between the meteorologists and rainmakers was characterised by mutual scepticism. The two groups negotiated on modalities of working together and successfully made joint seasonal weather forecasts that showed good convergence. The analyses using the three lenses of actor-narrative-interest enabled the study to tease out policy dynamics that are often ignored in climate change mitigation studies. Understanding these dynamics is important to ensure that climate change strategies are designed in congruence with local policy dynamics.

\begin{abstract}
1 Adaptation and indigenous knowledge in Kenya Available scientific evidence indicates that climate change presents very serious global risks and urgent action is needed to address it (IPCG 2007). In Kenya, climate change has been recognised as a serious threat to economic development and the government has set out to address it, as spelled out in various policy documents (Government of Kenya 2010). These efforts to address climate change are propelled by both domestic concerns as well as international obligations. The current national development blue print 'the vision 2030' recognises the need to address climate change. However, despite this high level recognition, the government is yet to formulate a consolidated comprehensive climate change policy. In a strict sense, a policy in Kenya has to be debated and adopted by the national assembly which normally takes a much longer time. In an effort to urgently deal with the threat of climate change, the government in consultation with various stakeholders formulated and adopted a comprehensive National Climate Change Response Strategy (NCGRS) in April 2010. The NCGRS makes bold recommendations on what the country has to do to reduce negative impacts of climate change and also how it can take advantage of existing opportunities. Climate
\end{abstract}

change has impacts across different sectors of the economy, hence the government faces challenges in coordinating segmented policies, laws and regulations that address climate change directly or indirectly in different sectors.

In the past, international efforts to deal with the problem of global warming and climate change concentrated on mitigation of greenhouse gas emissions. However, due to slow progress in achieving emission reductions and widespread changes in weather patterns, adaptation is now viewed as a crucial option to reduce vulnerability to climate change impacts. In recent years, indigenous peoples have been recognised as powerful knowledge-holders on climate change and key actors for developing policy to cope with and adapt to its effects. Indigenous knowledge (IK) has been defined as institutionalised local knowledge that has been built upon and passed on from one generation to another by word of mouth (Osunade 1994; Warren 1992). Much of this knowledge is a distinctive intellectual tradition that reflects close observation of the natural world not simply myth, legend or anecdote. It is the basis for local-level decision-making in rural communities in many parts of the developing world, including Kenya. IK has value not only for 
the culture in which it evolves, but also for scientists and planners striving to improve conditions in rural localities (Mundy and Compton 1991). The knowledge set is influenced by the previous generations' observations and experiments, and provides an inherent connection to one's surroundings and environment.

Responding to climate change puts a premium on the generation, interpretation and use of data and information in decision-making within communities, regions, countries and globally.

Too often, attempts to compare and contrast traditional ecological knowledge (TEK) with scientifically acquired data imply that indigenous people's way of knowing is inadequate in contrast with science (Sillitoe 2007). IK is viewed in climate change debates as having potential in helping communities adapt to climate change. However, there is also an unanswered question on whether or not or how it can be integrated with modern weather science, especially at the policy and planning level (Nyong et al. 2007; Macchi et al. 2008). Those who advocate the integration of IK in climate policy argue that this would lead to development of effective mitigation and adaptation strategies that are cost-effective, participatory and sustainable (Robinson and Herbert 2001; Hunn 1993). There are also arguments that IK being a distinct intellectual knowledge requires protection through policy.

In the Kenya context, IK is peripherally recognised in Kenyan policy documents as being important in adapting to climate change. Several policy documents explicitly recognise the important role that IK can play in dealing with climate change. The NCGRS states that as part of the strategy for enhancing ability to deal with climate change the country will '... inventory indigenous knowledge that has conventionally been used by local communities to cope with erratic climate...' (Government of Kenya 2010). The ongoing formulation of policy on 'traditional knowledge, genetic resources and traditional cultural expression' is another example of promotion of IK at the policy level. In the draft policy on wetlands it is explicitly stated that '... indigenous knowledge will be documented and incorporated in decision making...' In general, IK remains on the fringes of policy debates in Kenya, being viewed as ancient and historical rather than contemporary (Owuor 2007).
Many local communities and farmers in Africa have developed intricate systems of gathering, predicting, interpreting and decision-making in relation to weather. The Nganyi community in western Kenya has a highly developed system of IK that is critical in weather prediction, commonly known as 'rainmaking'. This article focuses on understanding the underlying policy processes arising from interaction between meteorological knowledge and IK-based weather prediction of a local community in western Kenya. The interaction between the two sources of knowledge was facilitated by a participatory action oriented project whose overall goal was to improve community adaptation to climate change. This study attempted to understand the underlying policy processes that arose from the project, including interaction of different actors, the policy narratives and interests they brought into the project and how they were reshaped by the project.

\section{The case study and methodology: linking meteorologists and rainmakers}

This article is based on analysis of policy processes around a Participatory Action Research (PAR) project in Kenya under the Climate Change Adaptation in Africa (CCAA) programme. The PAR project was undertaken under the auspices of the Intergovernmental Authority on Development (IGAD) Climate Prediction and Applications Centre (ICPAC) and a number of collaborators, such as the Kenya Meteorological Department (KMD), Kenya Industrial Property Institute (KIPI), the Great Lakes University of Kisumu (GLUK), the National Museums of Kenya (NMK) and the Nganyi community. The overall goal of the PAR project was to improve the ability of local communities to cope with climate variability by developing an effective warning and dissemination system. This system will be based on the combined knowledge and input from IK experts and meteorological scientists. The project proceeded from the premise that modern meteorological science provides reasonably accurate seasonal climate forecasts. Many local communities rely on IK to guide their planting, harvesting and other agricultural activities and to minimise climate risk. Despite the availability of these two sources of climate information, local communities were still vulnerable to climate change. To achieve its goals, the project sets out to demystify, document and show the relevance of IK among the Nganyi community for coping with 
impacts of climate change. The project documented the rainmaking process among the Nganyi and initiated the process of setting up a resource centre for sharing information.

The community was selected after a rigorous scoping exercise that involved checking on the existing indigenous climate knowledge in the country. The process involved scoping for information on communities that utilise IK to observe and predict weather. Selected members of the community were invited to a workshop to make presentations on their knowledge. The Nganyi were found to be among the most advanced in their climate observation knowledge in Kenya. The project began to create a link between the community of rainmakers and the KMD with a view of coming up with joint forecasts. The project therefore set out to investigate the integration of the two domains of knowledge and 'get the best from both worlds'.

As noted earlier, the Nganyi community of western Kenya was selected for the project because of their long history of 'rainmaking'. However, the rainmaking knowledge is shrouded in secrecy and controlled by a few community members within selected families who in the past used it to gain a position of privilege in the society. The holders of 'rainmakers' were therefore initially sceptical to share their knowledge with meteorological scientists from outside the community who sought their collaboration. The necessary mechanisms were put in place that allowed the project to take place and at the end of it, the two groups were able to make integrated forecasts disseminated by indigenous and modern methods.

The methodological framework used in this study was developed through the Research to Policy for Adaptation (RPA) project (see Naess et al., this IDS Bulletin), which frames policy processes as being conditioned and shaped by the political, social and economic context, as well as historical factors. This approach is contrary to the frequent view of a linear policymaking process in which rational decisions are taken based on available evidence by those with authority and responsibility for a particular policy area. Instead, drawing on other approaches to policy processes, the RPA approach considers political process as being complex, incremental and messy (Keeley and Scoones 2003; KNOTS 2006; Wolmer and
Scoones 2005; Gaventa 2006). The study worked with key stakeholders to identify the prevailing policy narratives/discourses, actors and networks and political and interest groups in weather prediction and reporting systems for climate change adaptation with particular focus on IK.

\section{Actors, narratives and interests}

The IGAD Glimate Prediction and Applications Centre (ICPAC) was a lead player in bringing together the other actors in the project. In particular, the leadership of Professor Laban Ogallo as prominent meteorological scientist and a champion of the role of IK in coping with impacts of climate change was critical. The KMD is the lead agency under the Ministry of Environment and Mineral Resources (MENR) concerned with weather and climate information gathering, interpretation and dissemination. $\mathrm{KMD}$ is the only agency recognised by the state as the provider of weather information and it relies on modern meteorological science in carrying out its duties. The use of nonstandardised scientific means for collecting and interpreting weather information is not part of KMD procedures. It is therefore not surprising that at the initial stages of engagement in the PAR project, KMD officials were sceptical of claims by the Nganyi rainmakers of their ability to accurately predict weather patterns.

Along with the KMD, the Nganyi rainmakers were major actors in the project. The Nganyi people are a clan found among the Banyore community who reside in the western province of Kenya. The community has developed advanced methods of weather prediction. The art of rainmaking takes place mainly in shrines which are established on the grave of 'rainmakers' of the past. The 'rainmakers' hold the knowledge as sacred that should only be confined to selected individuals who are male and with certain families and should not be shared with 'outsiders'. In the past, community members had to 'pay' the rainmakers to access the 'magical' power of the rainmakers. In essence, possessing the rainmaking knowledge bestowed the holders with a privileged position in the society that enabled them to have economic benefits. From an economic point of view, the 'rainmaking' knowledge was a 'private good' which other people had to pay a price to access. It is important to acknowledge how these economic benefits may have reinforced the persistence of IK over the years. The integration of IK with modern 
meteorology may mean considering putting the rainmakers on a salary in order to retain these benefits.

This informal market perspective was the prevailing narrative among the rainmakers before engagement with the PAR project. The arrival of the PAR project threatened the status quo because if the 'rainmaking' knowledge was shared openly, it would change from a private good to a 'public' or 'quasi-public' good. In fact, the 'rainmakers' were suspicious and sceptical of the project in the initial stages. As noted by one of the elders '... we had a problem in sharing knowledge with project partners as it was inherited especially the rain gauge and it would be a sign of betrayal for the community if it was shared'. It is also interesting to note that the attitude of the community towards IK was not homogeneous. Certain sections of the Christians in the community viewed the art of rainmaking as being 'witchcraft' and therefore 'unchristian' and belonging to the past era and should be abandoned. This counter-narrative is not necessarily very strong because there were many members of the community who did not see any conflict between traditional practices such as 'rainmaking' and the Christian faith.

The prevailing narrative among many educational institutions such as universities in Kenya is that IK does not qualify as a coherent intellectual knowledge strand worth of academic study. One exception is the Great Lakes University of Kisumu (GLUK), who were involved in the PAR project and offered a counter argument to this prevailing narrative, even developing curricula for teaching IK among its academic programmes. Participation of the GLUK in the project further reinforced the idea after the results of the weather prediction showed good convergence between the meteorologists and the 'rainmakers'. The convergence was not in the methods of weather information gathering, but on the actual weather predictions. The two groups carried out several rounds of seasonal forecasts separately and the results were strikingly similar. In essence, the PAR project provided a policy space for GLUK to showcase that IK is actually a field of knowledge worth studying and not just 'mystics'.

\section{Major findings}

The interactions between the different actors in the PAR project led to interesting findings. The
PAR project set out to explore the possibility of integrating IK as practised by the Nganyi community with modern meteorological science. At the beginning of the project, the rainmakers and meteorologist shared some mutual scepticism of each other. On one hand the rainmakers were sceptical of the motivation of the meteorologist; they feared that they would 'steal' their knowledge. The rainmakers viewed themselves as the custodians of the 'sacred' knowledge which they held on behalf of their community. At the point of entry into the PAR project, KMD was sceptical about the IK among the Nganyi; as noted by a leading officer at the KMD '... I had my doubts on the veracity of some of the claims the rainmakers made. But I was also aware that for an art or communitybased activity to survive it must be serving the community well'.

KMD is nationally acknowledged as the authoritative source of weather information in the country because it is scientific and verifiable. However, KMD is faced with the challenge of providing location-specific accurate weather prediction due to the thinly distributed number of weather recording stations on the ground. In addition, KMD has been providing information in rather technical language that is difficult for the farmers to understand and use for decisionmaking. Provision of accurate and easy-to-use information has gained more importance, especially due to the impacts of climate change that have disrupted the known weather patterns. At its inception, KMD had a bias in providing information for the aviation industry, hence its placement under the Ministry of Transport and Communication for a long period of time before being transferred to its current host ministry. The increasing importance of weather information especially due to the devastating impacts of weather disasters (droughts and floods) has led to the KMD occupying a more prominent role in climate debates. This change of the environment that the KMD is operating could partly explain why they were willing to work with traditional rainmakers, despite their initial scepticism. In essence, the changing political climate under which the KMD is operating provided a policy space for the KMD to work with other partners in the PAR project.

The two sides came to an agreement to deal with the concern of the 'rainmakers' by sharing duties. 
As noted by one of the elders, their concern for sharing knowledge was dealt with through '... segregation of duties where the elders were given time to forecast and share during the consensus meetings with the KMD'. The interaction between the KMD and the local rainmakers led to a change of narrative on the part of the KMD. They came to accept the rainmakers as nature observers and not just as mystics. The KMD came to realise that the rainmakers were nature observers and their predictions were largely informed by science, for example flowering patterns of trees. As one leading KMD officer notes '... some of their observations are grounded in science and the systematic way in which the observations are based on flora and fauna'. In a similar manner, the rainmakers also realised that they had something to gain from the project. One of the most important motivations for joining the project was that the project was a way of validating their knowledge. In addition, the rainmakers were also motivated by the promise that a resource centre would be established in their community. The setting up of a community centre and proposed set up of a weather observation station provided opportunity for continued collaboration and contributed towards trust building between the two groups.

The establishment of the resource centre not only influenced the 'rainmakers' but the Christians who were opposed to the practice of rainmaking. As noted by the areas' chief '... the project had changed views of the sceptics, especially the churchgoers, due to the presence of the resource centre and the worldwide recognition of the elders'. Direct benefits flowing to the community were critical to win their support for the project. The elders were also encouraged when their area member of parliament assured them of their support and attended the inaugural meeting during which the project was officially launched. From this perspective, the goodwill of the local political leader was also important in ensuring the success of the project. The rainmakers have become more willing to share information with the PAR project, unlike in the past when they held it as 'elite knowledge' for only a few people. In several meetings they also agreed that the project would add value to their work.

The convergence in prediction between the KMD and rainmakers offers prospects for integrating the two forms of knowledge. From the perspective of the rainmakers, ' $\ldots$ the KMD forecasts and theirs were almost similar with only slight variations. The consensus meetings had also helped change our view on the KMD forecasts as the variability is very small'. The convergence of the forecasts between the meteorologists and the rainmakers offers the potential for complementary roles between the KMD and rainmakers. The KMD has the competence in doing the large-scale/ meta predictions while the rainmakers could specialise in location-specific predictions. Despite the overall success of the interaction between the meteorologists and the rainmakers, there are issues that remain uncertain. For example, how relevant will IK remain in a situation of fastchanging climate? Will the accumulated knowledge of nature observation by the rainmakers keep up with the fast changing and increasingly unpredictable weather patterns?

\section{Conclusions}

The application of the RPA framework (Naess et al., this IDS Bulletin) helped in understanding the underlying policy process dynamics when the modern meteorological science and indigenous climate knowledge converge. The findings of the study provide useful insights that could guide the integration of IK in climate policies by understanding the local political context within which a policy-oriented project is undertaken. The framework introduced the idea of policy processes to the action research team working on the case study and provided lessons that can be used for scaling-up IK into national climate policies.

The convergence in the seasonal weather predictions between the meteorological scientists of the KMD and Nganyi rainmakers provides an open policy space for the advancement of IK in policy circles. Out of that process of rendering Nganyi knowledge visible and credible, there also emerged an engagement strategy which led to co-constructed weather forecasts that all groups involved could agree was coherent and useful. This convergence can be used to support the inclusion of IK as authentic knowledge that could be integrated in wider climate risk management policies.

Such efforts need ultimately to work towards establishing more prominently the presence and role of local knowledge in Kenya's climate change policy landscape. In order to achieve this, 
researchers must emulate the commitment to the task of championing IK seen in this case study. It will also require intellectual honesty by researchers to admit that they may become actors in the very processes they seek to describe, advocating one narrative over another (i.e. local knowledge is more, not less, relevant in a changing climate), seeking to yield influence with policymakers who control key decision-

\section{Note}

* Research for this article was conducted under the Research to Policy for Adaptation (RPA) project, funded through the Climate Change Adaptation in Africa (CCAA) programme. CCAA is a joint programme of the

\section{References}

Gaventa, J. (2006) 'Finding the Spaces for Change: A Power Analysis', IDS Bulletin 37.6: 23-33

Government of Kenya (2010) National Climate Change Response Strategy (NCGRS), Nairobi, Kenya: Ministry of Environment and Mineral Resources (MENR)

Hunn, E. (1993) 'What is Traditional Ecological Knowledge?', in N. Williams and G. Baines (eds), Traditional Ecological Knowledge: Wisdom for Sustainable Development, Canberra: Centre for Resource and Environmental Studies, Australian National University

IPCG (2007) Climate Change 2007: Synthesis Report. An Assessment of the Intergovernmental Panel on Climate Change, Cambridge: Cambridge University Press

Keeley, J. and Scoones, I. (2003) Understanding Environmental Policy Processes: Cases from Africa, London: Earthscan/James \& James

KNOTS (2006) Understanding Policy Processes: A Review of IDS Research on the Environment, Knowledge, Technology and Society Team, Brighton: IDS

Macchi, M.; Oviedo, G.; Gotheil, S.; Cross, K.; Boedhihartono, A.; Wolfangel, C. and Howell, M. (2008) Indigenous and Traditional Peoples and Climate Change, Issues Paper, IUCN, http://cmsdata.iucn.org/downloads/indigenous _peoples_climate_change.pdf (accessed 27 January 2011)

Mundy, P. and Compton J.L. (1991) Indigenous Communication and Indigenous Knowledge, Development Communication Report 74, making spaces or to force more inclusive spaces where these are lacking.

Further research is recommended to pave the way for a replicable model of research-policy engagement to connect with other marginalised or excluded groups in Kenya who have

knowledge and practice to contribute to efforts to understand how to adapt to climate change.

International Development Research Centre (IDRC) and the UK's Department for International Development (DFID). The views expressed here are the views of the authors and do not represent the views or policies of IDS, DFID, or IDRC.

1991/3, Arlington, VA: Clearinghouse on Development Communication, www.mamud.com/Docs/ic_and_ik_dcr.pdf (accessed 30 January 201 $\overline{1}$ )

Nyong, A.; Adesina, F. and Elasha, O.B. (2007)

'The Value of Indigenous Knowledge in Climate Change Mitigation and Adaptation Strategies in the African Sahel', Mitigation Adaptation Strategies and Global Change 12: 787-97

Osunade, M. (1994) 'Indigenous Climate Knowledge and Agricultural Practices in South Western Nigeria', Malays Journal of Tropical Geography 1: 21-8

Owuor J.A. (2007) 'Integrating African Indigenous Knowledge in Kenya's Formal Education System: The Potential for Sustainable Development', Journal of Contemporary Issues in Education 2.2: 21-37

Robinson, J. and Herbert, D. (2001) 'Integrating Climate Change and Sustainable Development', International Journal of Global Environmental Issues 1.2: 130-48

Sillitoe, P. (2007) 'Local Science v. Global Science: An Overview', in P. Sillitoe (ed.), Local Science vs Global Science: Approaches to Indigenous Knowledge in International Development, New York: Bergahn Books

Warren, D.M. (1992) 'Using Indigenous Knowledge in Agricultural Development. The Case of Ara Community', Occasional Paper 1, Ibadan: African Resource Center for Indigenous Knowledge

Wolmer, W. and Scoones, I. (2005) An Introduction to Policy Processes, Brighton: IDS 